\title{
Editorial
}

\section{Challenges and opportunities in environmental biosafety research}

\author{
Bao-Rong LU ${ }^{1}$ and Jeremy SWEET ${ }^{2}$ \\ 1 Ministry of Education Key Laboratory for Biodiversity and Ecological Engineering, Institute of Biodiversity Science, Fudan University, \\ Handan Road 220, Shanghai 200433, P.R. China \\ 2 Sweet Environmental Consultants, 6 Green Street, Cambridge CB24 5JA, UK
}

Since the first commercial release of genetically modified (GM, also referred to as genetically engineered, GE) crops in the middle of 1990 s, the research and development of transgenic biotechnology has made dramatic progress. To date, global cultivation area of GM crops has exceeded 120 million hectares (James, 2009) with extensive cultivation of herbicide-tolerant soybean and canola, insect-resistant cotton and maize, as well as other GM products, which has offered great opportunities for agriculture development. However the extensive commercial releases of GM plants have caused concerns and debates over their biosafety, both for consumers and the environment. The heat of debates over environmental biosafety issues has been fuelled by certain new developments, most recently proposal to farm GM salmon and the issuance of biosafety certificates for two insect-resistant GM rice lines in China. Therefore, biosafety issues related to the commercialization of GMOs are as important today as when the technology was first launched.

\section{ENVIRONMENTAL BIOSAFETY RESEARCH FOR THE FIRST GENERATION OF GMOS}

Research on environmental biosafety related questions has been actively associated with the commercial cultivation of GM plants in the past fifteen years. Research has focused on (i) the effects of insect toxic traits (e.g. the Bacillus thuringiensis $[\mathrm{Bt}]$ ) on non-target organisms (e.g., O'Callaghan et al., 2005; Oliveira et al., 2007; Poppy, 2000); (ii) the potential ecological impacts caused by transgene flow to crop landraces and wild relatives (e.g., Lu and Snow, 2005; Mercer et al., 2006; Wilkinson et al., 2000); and (iii) interactions and influences of transgenes and GM plants on biodiversity, ecosystem functions, and soil microbes (e.g., Bellon and Berthaud, 2004;
Giovannetti et al., 2005; Oliveira et al., 2007), etc. The large amount of data and results that have been accumulated through these studies have significantly increased our knowledge and understanding of the key environmental biosafety issues concerning the release of GM crops. This in turn has provided a sound scientific base for GM product developers, regulators, and decision makers to determine whether particular GM plants can be safely deployed in specific environments. So far, no major unexpected negative environmental hazard has been caused by the cultivation of first generation of GM plants, confirming the results of the biosafety assessments that have been conducted around the world.

\section{THE CHALLENGE OF ENVIRONMENTAL BIOSAFETY ASSESSMENT FOR THE NEW BIOTECHNOLOGY PRODUCTS}

The speedy progress of molecular biology and biotechnology has greatly promoted the development of the second generation of GMOs. These include GMOs with multiple or stacked traits either through the transformation of a number of transgenes in one construct or combinations of transgenes in a single plant by sexual hybridization (Taverniers et al., 2008); GMOs developed for pharmaceutical and industrial use or molecular farming (Spök et al., 2008), RNAi technology for crop improvement (Mansoora et al., 2006), total genome modification (Slade and Knauf, 2005), and synthetic genomics (Moose and Mumm, 2008), etc. The production and commercialization of these biotechnology products provide new challenges for the environmental biosafety assessment. For example, the "SmartStax" eight-gene-stacked combination in GM corn is already scheduled for commercial release in 2010 (Coons, 2009). 
The environmental risk assessment of such products will need to determine if there are interactions among the stacked genes and will need to include consideration of the potential environmental impacts of the stacked events as well as all the segregants that will occur following cultivation. In addition, work on developing GM animals, including insects, fish, and farm animals is currently accelerating and these will present some entirely new environmental issues for consideration.

\section{THE OPPORTUNITIES OF ENVIRONMENTAL BIOSAFETY RESEARCH}

These new GM products will provide new opportunities for original research studying their environmental impacts. The journal of Environmental Biosafety Research (EBR) offers a particular forum for scientists working on environmental biosafety related issues. EBR has published many high-quality results that are widely cited by scientists working in the field of environmental biosafety research. EBR will be a venue for publishing articles associated with the new generations of GMOs, to describe their research and results. In addition it provides a forum to review, discuss and debate research results and their implications for environmental biosafety. EBR has made some new developments to respond to these developing situations:

- A new Editorial Board has been established with members covering a wide range of expertise (see the Editorial Board in this issue). The international editorial team is composed of members representing research institutions, biosafety regulators, and industry, and we look to this editorial board maintain the high standard of research articles in the field of environmental biosafety research;

- EBR will launch an online submission system applying Editorial Manager (EM) in 2011. The installation of online submission system will provide close monitoring and efficient management of manuscript submission and reviewing, and a quicker through put of manuscripts particularly after a manuscript has been reviewed.

- The publisher of EBR has had a partnership with Cambridge University Press (CUP) since September 14, 2010. The cooperation of both publishers will maximize the dissemination of scientific research through Cambridge's global footprint (the announcement and details of the partnership of EDP Sciences with CUP can be found at the following address: http://publications.edpsciences.org/index. php?option $=$ com_content \&task $=$ view $\&$ id $=337 \&$ Itemid=356\&lang=en). The partnership with CUP further expands EDP Sciences' reach internationally while consolidating its position as a leading French science publisher. This will promote a more healthy publication of every EBR issue in a timely manner and reaches more international audience.

The journal EBR was established in October, 2002 as a professional and scientific journal that is supported by the International Society for Biosafety Research (ISBR). EBR offers a special venue for publishing research results for environmental biosafety related issues. Indeed, EBR has published many excellent articles based on solid research results in this field. This is reflected in approximately 3500 accesses of abstracts per month and approximately 1700 PDF downloads each month, particularly of papers with free access. These articles have provided useful information and references concerning environmental biosafety issues for scientists, policy makers, and stakeholders who are interested in environmental biosafety. As always, EBR aims to continue its endeavor to publish scientific research of a high standard and also to publish reviews and commentaries in the field of environmental biosafety research.

The healthy growth of EBR is made possible support from scientific authors and the editorial team of EBR. We encourage researchers to contribute their manuscripts, reviews, and commentaries to the journal, so that it continues to be a special and professional forum for environmental biosafety research widely read and referenced by scientists, researchers, regulators, and stakeholders around the world.

\section{REFERENCES}

Bellon MR, Berthaud J (2004) Transgenic maize and the evolution of landrace diversity in Mexico: The importance of farmers' behavior. Plant Physiol. 134: 883-888

Coons R (2009) U.S., Canadian regulators OK SmartStax, reduce refuge requirements. Chemical Week 171: 11

Giovannetti M, Sbrana C, Turrini A (2005) The impact of genetically modified crops on soil microbial communities. Riv. Biol. 98: 393-417

James C (2009) Global status of commercialized biotech/GM Crops: 2009. ISAAA Brief No. 411, ISAAA, Ithaca

Lu B-R, Snow AA (2005) Gene flow from genetically modified rice and its environmental consequences. BioScience 55: 669678

Mansoora S, Amina I, Hussaina M, Zafara Y, Briddona RW (2006) Engineering novel traits in plants through RNA interference. Trends Plant Sci. 11: 559-565

Mercer KL, Shaw RG, Wyse DL (2006) Increased germination of diverse crop-wild hybrid sunflower seeds. Ecol. Appl. 16: $845-854$ 
Moose SP, Mumm RH (2008) Molecular plant breeding as the foundation for 21 st century crop improvement. Plant Physiol. 147: 969-977

O'Callaghan M, Glare TR, Burgess EPJ, Malone LA (2005) Effects of plants genetically modified for insect resistance on non-target organisms. Annu. Rev. Entomol. 50: 271-292

Oliveira AR, Castro TR, Capalbo DMF, Delalibera I (2007) Toxicological evaluation of genetically modified cotton $\left(\right.$ Bollgard $\left.^{\circledR}\right)$ and Dipel ${ }^{\circledR}$ WP on the non-target soil mite Scheloribates praeincisus (Acari: Oribatida). Exp. Appl. Acarol. 41: 191-201

Poppy G (2000) GM crops: Environmental risks and non-target effects. Trends Plant Sci. 5: 4-6

Slade AJ, Knauf VC (2005) TILLING moves beyond functional genomics into crop improvement. Transgenic Res. 14: $109-115$
Spök A, Twyman RM, Fischer R, Ma JKC, Sparrow PAC (2008) Evolution of a regulatory framework for pharmaceuticals derived from genetically modified plants. Trends Biotechnol. 26: 506-517

Taverniers I, Papazova N, Bertheau Y, De Loose M, HolstJensen A (2008) Gene stacking in transgenic plants: towards compliance between definitions, terminology, and detection within the EU regulatory framework. Environ. Biosafety Res. 7: $197-218$

Wilkinson MJ, Davenport IJ, Charters YM, Jones AE, Allainguillaume J, Butler HT, Mason DC, Raybould AF (2000) A direct regional scale estimate of transgene movement from genetically modified oilseed rape to its wild progenitors. Mol. Ecol. 9: 983-991 